\title{
EDUCACIÓN CONTINUADA
}

\author{
Mauricio Wagner V. MD*
}

La educación continuada y en especial en salud ha evolucionado haciéndose más integral al involucrar en un mismo programa diferentes campos de acción y complementado con las modalidades disponibles, logrando un alcance antes inesperado y cumpliendo así con los requisitos del estudiante que cada día son más extensos y especializados.

Después de haber realizado más de 500 programas de diferentes tópicos relacionados con la salud, quisimos capitalizar el trabajo realizado buscando oportunidades de mejora que nos llevaran a preservar y mejorar la calidad de los programas. Iniciamos depurando los procesos y procedimientos para poder desde el diseño y desarrollo hasta la entrega final de un programa, para articular todos los participantes en el proceso estando alineados con los procedimientos institucionales.

Una vez realizada esta labor, de manera voluntaria nos lanzamos a buscar la certificación ISO 9001-2008, norma que es editada por la Organización Internacional para la Normalización, ISO es la sigla en Inglés de International Organization for Standarization. Está regida por los mismos principios que la mayoría de las normas internacionales y a su vez cumple con los requisitos legales que se exigen en Colombia. Con el beneplácito del Consejo Superior y el apoyo de la rectoría decidimos conseguir esta certificación, la cual comprende los conceptos y requisitos que debe cumplir un sistema de gestión de la calidad, en nuestro caso desde el desarrollo y diseño hasta la finalización de cada programa, cumpliendo con los objetivos de la

* Director de Educación Continuada, Fundación Universitaria de Ciencias de la Salud. Bogota DC, Colombia. organización, orientado a satisfacer a los clientes y mejorar siempre demostrando un compromiso institucional en la calidad de nuestra oferta.

En educación continuada la dinámica de la actividad es muy ágil y exigente, a la vez necesita del concurso de casi todas las dependencias de la universidad como servicios administrativos, recursos humanos, gestión de proyectos, contabilidad, UVA, audiovisuales, diseño e impresos, sistemas, auditoria, gerencia y rectoría, lo que implicó un trabajo arduo de todas estas dependencias en pro de la certificación, fomentando aun más la cultura de calidad ya existente en la universidad y que después nos servirá para la certificación institucional.

Esta dinámica de la actividad en educación continuada hace que el trabajo estratégico y operativo sea muy versátil e intenso como ya lo comenté, al requerir el concurso de muchas dependencias, manejar varios programas al mismo tiempo con diferentes requisitos en diferentes áreas del saber, con cambios constantes en el desarrollo por las múltiples variables propias de la actividad que exigen soluciones al momento, haciendo que quienes laboran allí sean recursivos, ágiles, efectivos y polifacéticos para poder llevar a término todos los programas con el compromiso esperado y cumpliendo con el sistema de gestión de calidad.

La obtención de la certificación además de ser un proceso muy exigente, no solo formativo para la institución que lo logra sino que de una manera indirecta y desde una visión externa ayuda para evaluar las mejoras logradas, el adecuado análisis de la información y así tener más opciones que favorezcan tomar mejores decisiones. 
La otorgación del certificado con la norma ISO 9001:2008 es una muestra del gran compromiso institucional adoptando procesos de transformación y la continua búsqueda de estándares de calidad en los programas, para así lograr la excelencia deseada y que los mas de 40.000 estudiantes y 600 programas realizados durante estos seis años signifiquen la permanente búsqueda de la calidad y poder continuar con el reto que es el mantenimiento y mejora de los estándares de calidad que aseguren la continuidad de la certificación.
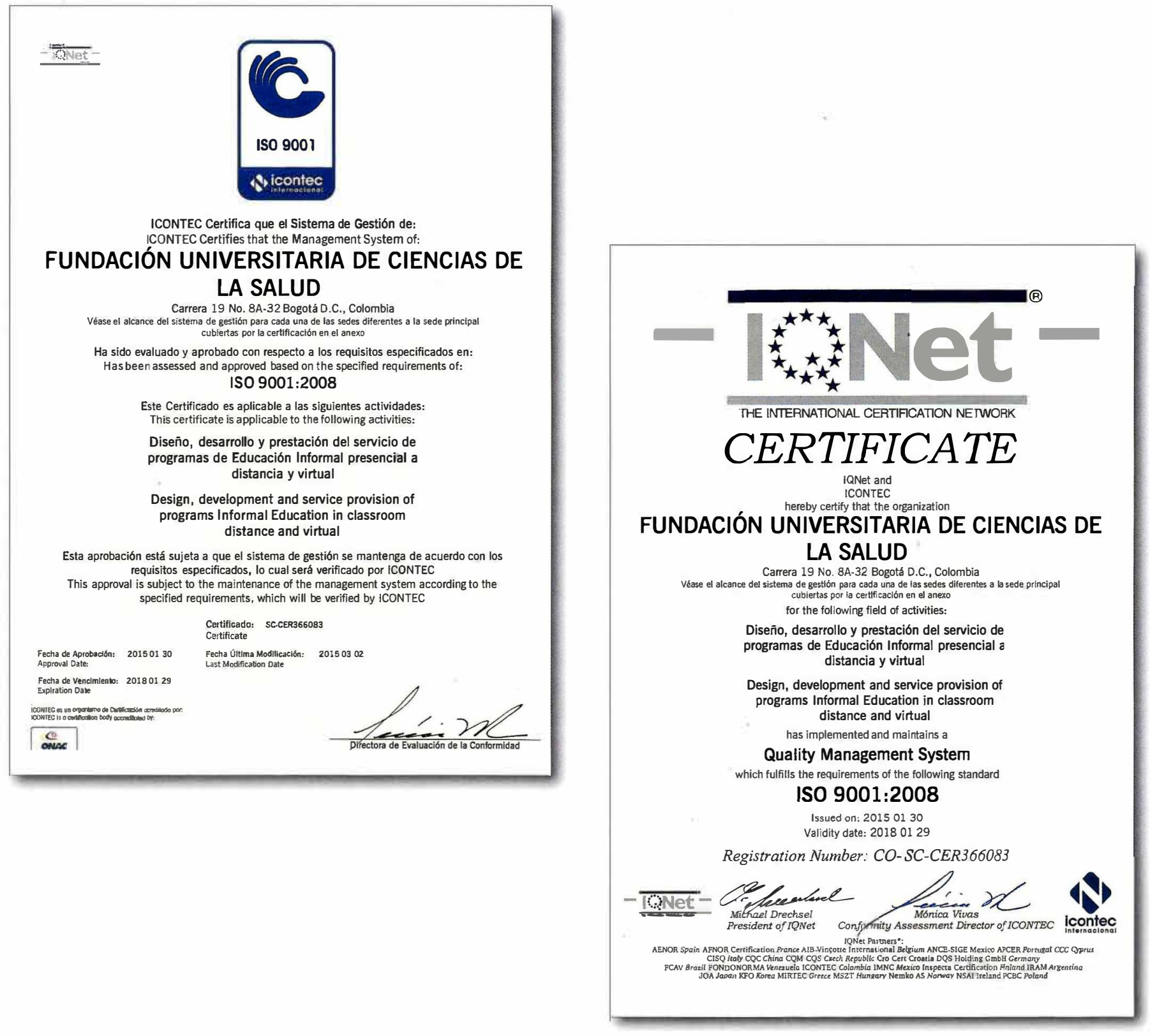